\title{
Obituary: Francis C. Colpaert, Ph.D. (1950-2010)
}

\author{
Wouter Koek • James H. Woods • Charles P. France
}

Published online: 1 February 2011

(C) Springer-Verlag 2011

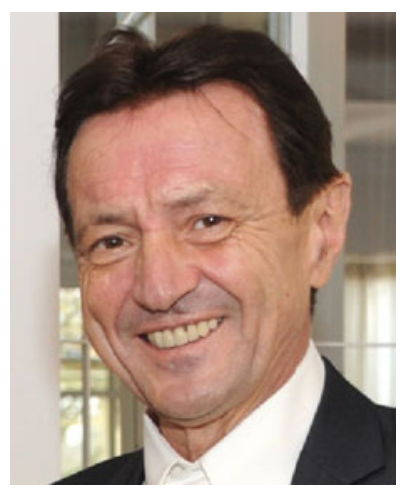

On a sunny Sunday afternoon, in the French countryside, late August 2010, we drove from Francis' house in Puylaurens to Les Marronniers, which had become his favorite restaurant in the region based on his extensive and thorough sampling. Trusting the judgment of the cook, he ordered carte blanche au chef for all of us. It was the last of the many memorable meals we shared with Francis. Although ill, he enjoyed the food, his friends, and talking science, as always. Two months later, on October 15, Francis died in Castres, France, of complications from pancreatic cancer.

W. Koek $(\bowtie) \cdot$ C. P. France

Departments of Psychiatry and Pharmacology,

University of Texas Health Science Center at San Antonio,

7703 Floyd Curl Drive, Mail Code 7792,

San Antonio, TX 78229, USA

e-mail: koek@uthscsa.edu

\section{J. H. Woods}

Department of Pharmacology,

University of Michigan Medical School,

1301 MSRB III, 1150W. Medical Center Drive,

Ann Arbor, MI 48109, USA
Fifty-nine years earlier, on November 12, 1950, Francis was born in Herentals, in the Flemish part of Belgium. From 1968 to 1972, he received training in psychophysiology at the Catholic University of Leuven, Belgium. After additional training at the University of Groningen (The Netherlands), he joined Janssen Pharmaceutica (Beerse, Belgium) in 1973. Dr. Paul A.J. Janssen introduced Francis to neuropharmacology and supervised, with Prof. Dr. David de Wied, the work on the discriminative stimulus properties of opiates that earned Francis a Ph.D. in pharmacology from the University of Utrecht (The Netherlands). David de Wied remembered Francis as "an

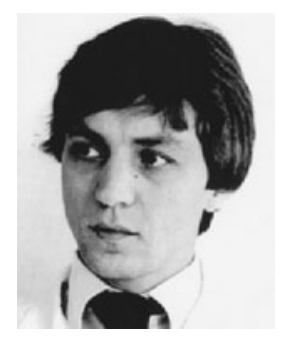

excellent scientist and a skillful and technically highly gifted young man" and speaking also on behalf of Jan van Ree mentioned that "We don't know whether he learned something from us." Francis certainly did, shown by having been an excellent mentor himself to many, including Theo Meert, Jean de Vry, Rob van den Hoogen, and Liesbeth Bruins Slot. According to Liesbeth, "Mentors guide the journey of our lives: they cast light on the way ahead, warn us of lurking dangers, and point out unexpected delights along the way." Francis created many opportunities for others to join the exciting new area of research described in his thesis. He organized three international drug discrimination meetings, in 1978 with John Rosecrans, in 1982 with Jef Slangen, and in 1986 with Bob Balster. In addition to fruitful scientific exchanges, these meetings and those of the European 
Behavioural Pharmacology Society, founded by Francis and Ian Stolerman, started many lifelong friendships with Francis, among others, and among us.

Since 1973, Francis worked in the pharmaceutical industry with Paul Janssen in Beerse (Belgium) until 1986, with Jacques Servier in Paris (France) from 1986 to 1990, and with Pierre Fabre in Castres (France) from 1990 onwards. In Beerse, he worked in the pharmacology department and crucially contributed to the discovery of the peripheral opiate and antidiarrheal loperamide (Immodium ${ }^{\circledR}$ ), epidural sufentanyl in anesthesiology, and the novel antipsychotics pirenpirone and risperidone (Risperdal ${ }^{\mathbb{R}}$ ). In Paris, he created a new neurobiology division. As its director, Francis interacted directly with medicinal chemistry, producing compounds such as the novel selective 5-HT2C ligand S 12361, the antipsychotic S 14066, and the high-efficacy 5-HT1A receptor agonist S 14506. In Castres, Francis' first mission as research director was to renovate, restructure, and redefine preclinical drug discovery research at Pierre Fabre. More than 100 new positions were created, making the Centre de Recherche Pierre Fabre an autonomous and strategically reshaped center devoted to medicinal chemistry and pharmacology in cancer, central nervous system, and cardiovascular disease. Currently, a dozen compounds in these three therapeutic areas are in various (preclinical to phase III) stages of development. In 2004, this portfolio called for a reorganization of both research and development (R\&D) with the creation of three separate R\&D units. Since 2004, Francis assisted the overall $R \& D$ president as scientific director. Throughout his career, Francis impacted the lives of many people by creating new opportunities for them. His collaborators were free to decide what to work on, as long as they delivered quality work evidenced by peer-reviewed publications. As he knew from his interactions with Paul Janssen, Jacques Servier, and Pierre Fabre, getting carte blanche is a sign of trust and is very motivating, which is why Francis gave it to many others.

Francis authored more than 300 publications, which is an impressive number by any standard, especially for someone working in industry instead of academia. It shows that Francis was an uncommon scientist. His science and drug discovery always reinforced each other. Developing drug discrimination as an animal model of the subjective drug effects in humans led to the discovery that the opiate antidiarrheal loperamide did not have such effects and, therefore, did not have abuse potential. Francis' drug discrimination studies also provided the foundation for novel ideas about magnitude of receptor activation, leading to identifying the antipsychotic risperidone as a pure antagonist of LSD. His drug discrimination studies generated novel ideas about opiate tolerance, which guided the identification of $\mathrm{F} 13640$ to produce long-lasting pain relief, and novel ideas about state-dependent learning, which guided Francis' drug discovery efforts to treat Parkinson's and Alzheimer's disease.

Francis was an uncommon scientist because, unlike many of us, he was a good thinker. Most scientists think for relatively short periods of time, because it is so difficult. Francis didn't seem to find thinking difficult and spent more time thinking and was better at it than most of us. Also, Francis was incredibly persistent. He had good ideas, knew they were good ideas, and there was not much you could do to convince him otherwise. It is difficult to know how long it will take his nontraditional notions of how drugs act to become accepted. We can all hope that, while we are waiting, his ideas will lead to new therapeutics for a range of serious diseases because that, of course, is a real test and a cause that Francis was most devoted to.

On a sunny Thursday morning in the Flemish countryside, October 21, 2010, we were driving past Herentals, Francis' birthplace, to Kesselt, where the funeral was to be held. Sun rays through the stained glass brightened the interior of the Sint-Michiels church. Readings by relatives and friends spoke of Francis' love of life and the influence he had on the lives of many through his unbridled trust. Francis will continue to impact the lives of others, through the countless memories he leaves behind and through his many scientific contributions that may help to relieve pain and treat cancer. Francis is survived by his mother Anna, his wife Anne, his son Michael, his daughter Sophie, and his grandson Yann. 